\title{
RADIATION DAMAGE IN THE DEVELOPING GERM CELLS OF DROSOPHILA VIRILIS
}

\author{
By Mary L. Alexander and Wilson S. Stone
}

GENETICS FOUNDATION, DEPARTMENT OF ZOÖLOGY, UNIVERSITY OF TEXAS

Communicated by J. T. Patterson, September 29, 1955

Since 1945 a great many studies have been made to determine the relation between the amount of damage induced by ultraviolet or ionizing radiations and the chemistry of the cell. One important biological activity which involves both chemical and genetic changes in the cell is the process of maturation with gamete formation. Alexander ${ }^{1}$ has presented new data and reviewed older experiments which prove that the mutation rate per roentgen unit X-ray dose is lower in spermatogonia than in mature sperm of Drosophila melanogaster. Auerbach ${ }^{2}$ and Lüning $^{3}$ had shown that the mutation rate and rearrangement rate varied during the maturation cycle. Stone, Haas, Alexander, and Clayton ${ }^{4}$ showed that major differences in rearrangement rate occurred through the maturation cycle of Drosophila virilis males. The frequency of rearrangement was influenced by the chemistry of the cell. This paper presents data showing the relation of genetic damage to dosage and to differences in gaseous environment.

Materials and Methods. Strain No. 1801.1 of $D$. virilis from Texmelucan, Mexico, was used as the standard stock. The mutant marker stock used to score translocations contained broken ( $b$, on chromosome 2), tiny bristle, gapped ( $t b, g p$, on 3 ), cardinal ( $c d$, on 4), and peach (pe, on 5). The microchromosome 6 and the $\mathrm{X}$ chromosome were not marked, but translocations involving the $\mathrm{Y}$ were checked. Chromosome damage was scored genetically from backcrosses as translocations produced between any two $\left(T_{2}\right)$ or more $\left(T_{3}, T_{4}\right.$, etc.) major chromosomes $(\mathrm{Y}, 2,3$, 4, and 5). Dominant lethals were determined from the number of eggs laid that failed to develop into pupae. In some crosses samples of freshly laid eggs were examined for sperm, using the smear technique devised by Patterson, Stone, and Griffen. $^{5}$ This differentiates between lack of development due to dominant lethals and that due to unfertilized eggs (see experiment 12).

All tests were carried out at $1-3^{\circ} \mathrm{C}$. Pretreatment, irradiation, and posttreatment were done in the same gases, except in experiment $13 b$, where CO replaced $\mathrm{O}_{2}$ in posttreatment (see Table 2). The dose to adults was delivered at 1,000 $\mathrm{r}$ per minute $(250 \mathrm{kv}$., 15-ma. X-rays) for the necessary interval, except in experiment 15 , where two $500-r$ doses were separated by one minute. The pupae received $1,000 \mathrm{r}$ at $173 \mathrm{r}$ per minute from an X-ray machine operating at $50 \mathrm{kv}$, 5 ma., with a $1-\mathrm{mm}$. aluminum filter. Tests using $\mathrm{CO}$ were carried out in the dark.

When adults were tested (experiments 12, 13a, 13b, 14, and 15), males 19-21 hours old were X-rayed and mated individually to three mature females. After the 5 days required for $D$. virilis males to mature, the males were remated individually to three mature females, consisting of one normal and two marker females. The males were remated to three such females every 2 days for eight periods. After the male was removed, the two types of females were separated. The number of eggs laid by the normal females were counted each day for 3 or 4 days and com- 
pared with the number of pupae that developed as a measure of dominant lethals. $F_{1}$ males from the marker females, usually six to ten from each $P_{1}$ male, were backcrossed to marker females, and translocations were scored in $\mathbf{F}_{2}$ from unusual genetic linkages. The fertility of $F_{1}$ males was recorded to be sure that the data were not biased by excessive sterility. The first period, A, represents the first effective sperm samples obtained from mature males, and the testing continued through period $\mathrm{H}$, when the males were 20-21 days old. This procedure tests gametes irradiated at different stages of development from nearly mature sperm (A) back to spermatogonia $(\mathrm{H})$.

In tests 17 and 18, old larvae were allowed to pupate on filter paper over a 20-hour interval and then were set aside for 90 hours. These 90-110-hour pupae were divided into two lots: one was pretreated 8 hours in $\mathrm{N}_{2}$, irradiated with 1,000 r, and then posttreated for 2 hours; the other was treated similarly, except that $\mathrm{CO}$ was used in place of $\mathrm{N}_{2}$ throughout the test.

Results.-The results of the tests are given in Tables 1 and 2. Most of the information is plotted on Figures 1-4. Experiment 12 is taken from an earlier paper ${ }^{4}$ to allow a three-point dosage comparison. Three control egg-development tests

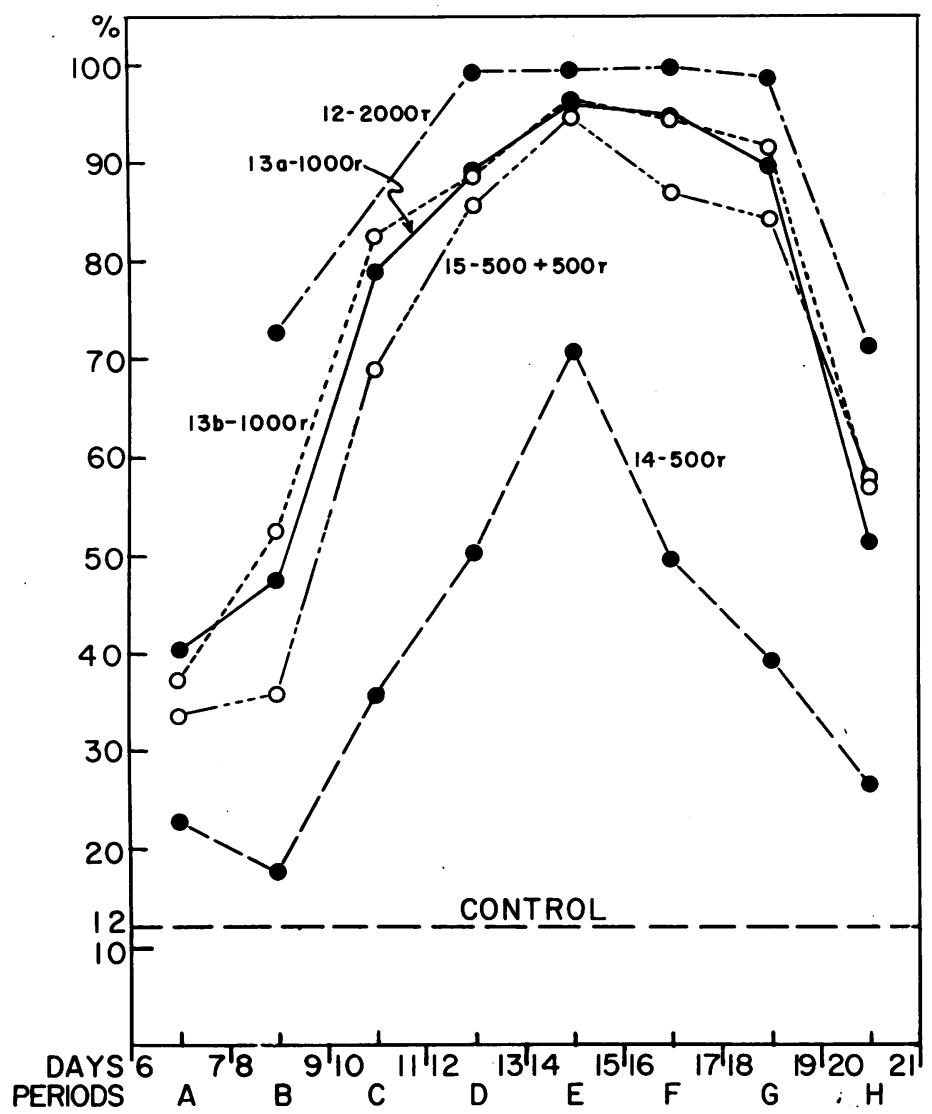

Frg. 1.-The relation between $\mathrm{X}$-ray dosage (in $\mathrm{O}_{2}$ ) and the frequency of dominant lethals produced in different stages of the developing male germ cell. 
were run (Table 1). The first two were run like the experimental series. In these two, 12.0 per cent of 27,081 eggs failed to develop. This 12.0 per cent control level is indicated on Figure 1. Dominant lethals due to irradiation account for the major fraction of deaths in the experimental series. The third test was made with a newly selected, very viable stock to determine whether the egg development on successive days still showed the increase found in the first controls and in the experimental material. There was no obvious increase in egg development as the male aged, as shown by comparing the productivity of the first female mated with that of the second female mated the next day, etc. There was a consistent increase in hatch on successive laying days from all females.

TABLE 1

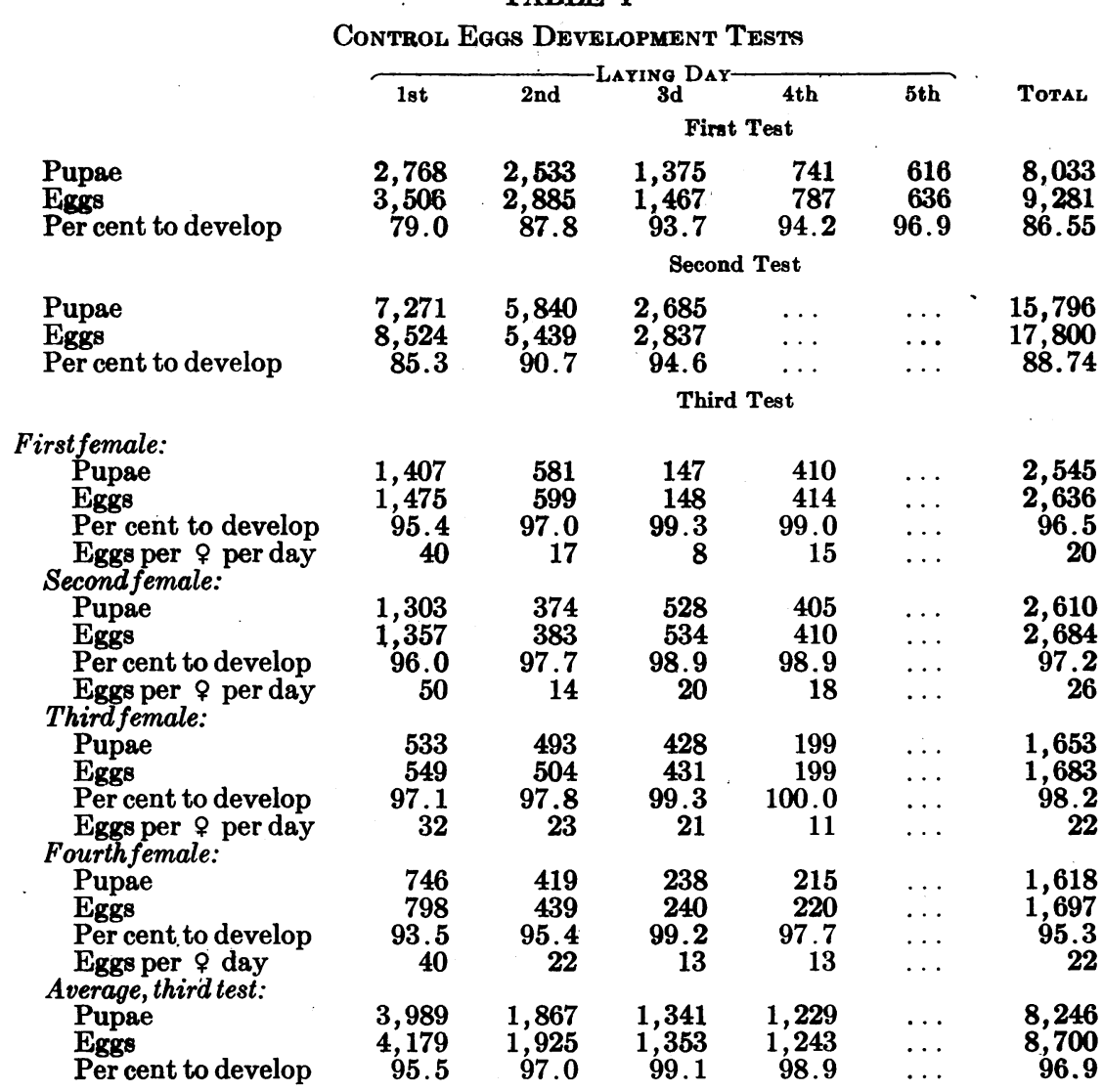

The rate of spontaneous translocations is very low. In all of our tests so far published, 4, 6, 7 including these tests, we have found only four spontaneous translocations. These were detected as a cluster of identical translocations from a tested $F_{1}$. Three involved the chromosomes of the female marker stock, which was not $\mathrm{X}$-rayed; in the other, all progeny of an $\mathrm{F}_{1}$ male carried the same translocation. This spontaneous rate is too low to influence the experimental data.

The results of experiments 12-15 are in agreement, whether radiation damage is assayed as recoverable translocations or as dominant lethals (Table 2 and Figs. 1 
and 2). The first sperm utilized (stage A, when the males are 6-7 days old) were nearly mature sperm at irradiation. Clayton (unpublished) reports that the tails of the sperm in $D$. virilis males less than 24 hours old have not coiled, and therefore some processes in sperm development are incomplete. Dominant lethals increased in frequency from stage $A$ to stage $E$ and then decreased until stage $H$ (Fig. 1). Even at $500 \mathrm{r}$ all stages show a frequency of lethals above control values.

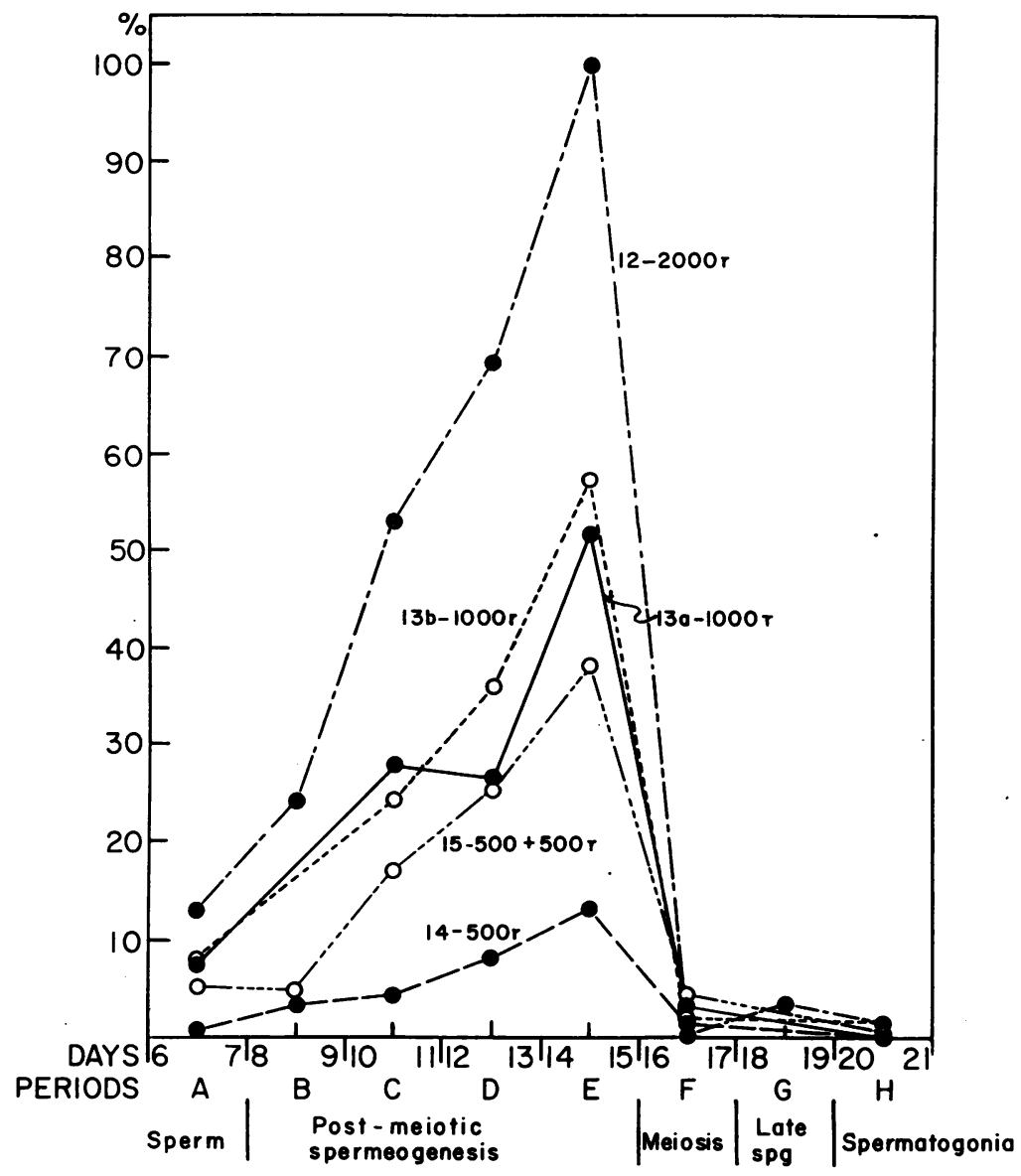

Fig. 2.-The X-ray dosage (in $\mathrm{O}_{2}$ ) translocation frequency in the malegerm-cell cycle. The approximate limits of the different stages are shown.

The damage at 2,000 $\mathrm{r}$ was too great to show relations from stage $\mathrm{C}$ to stage $\mathrm{G}$, as too few survived in these stages, but a direct relation to dosage still existed in stage H.

The translocation rate showed the same increase in damage from stage A to stage $\mathrm{E}$, then dropped to around 1 per cent for stages $\mathrm{F}, \mathrm{G}$, and $\mathrm{H}$. These last three stages showed that marked differences in the two measurements of genetic damage for dominant lethals were frequent when few translocations occurred. In both types of test the maximum damage occurred in period E, 14-15 days after the 19-21hour-old males were irradiated. 
The 4-5-day-old pupae in experiments 17 and 18 gave similar curves for dominant lethals and translocations, but the period of peak damage was shifted from stage $\mathbf{E}$ to stage B (Fig. 3). Damage measured as dominant lethals continued through period $F$, but the material treated in nitrogen (experiment 17) was about control level by period G. This is the only test where damage, measured as dominant lethals, drops to the control level. Damage was produced at all stages where the pupae were irradiated in carbon monoxide, even in period $G$ (experiment 18). The absence of oxygen in these two experiments (17 and 18) reduced the radiation

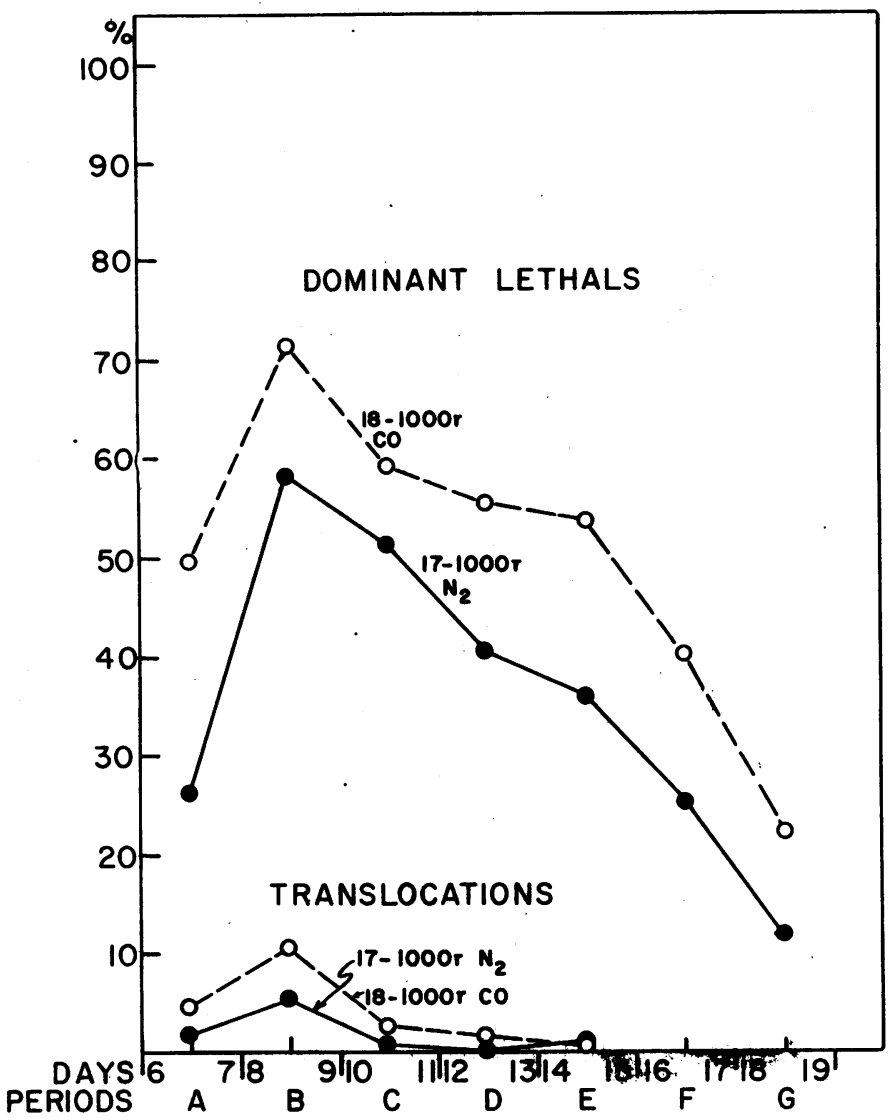

Fra. 3.-The genetic damage in the different stages from irradiating pupae (in $\mathrm{N}_{2}$ or $\mathrm{CO}$ ).

effect to a much lower level than in the other tests using $1,000 \mathrm{r}$. Carbon monoxide increased the damage above that in nitrogen at all stages during the meiotic cycle. Neither of these tests of treated pupae show the characteristic reduction in $P_{1}$ male fertility in periods $F$ and $G$ found in the adult 1,000-r test (experiments $13 a, 13 b$, and 15).

Discussion.-The work on the meiotic cycle in Drosophila has been reviewed by Cooper. ${ }^{8}$ The designation of the meiotic cycle in $D$. virilis, shown on Figure 2, is approximated by analogy with other insects, including $D$. melanogaster. The vari- 
ation in response to irradiation is not restricted to insects but is also characteristic of plant material, as was shown in Trillium erectum for rearrangements by Sparrow ${ }^{9}$ and in maize for mutations by Singleton. ${ }^{10}$ Bonnier and Lüning ${ }^{3,11}$ demonstrated a cycle of sensitivity during spermatogenesis both for breaks and for mutations in D. melanogaster. Auerbach ${ }^{2}$ established differences in mutation frequency in relation to stages of the meiotic cycle in $D$. melanogaster. She used crossing over in the male induced by the X-ray treatment to prove which meiotic stage gave a particular mutation frequency. Adult males were irradiated, placed individually

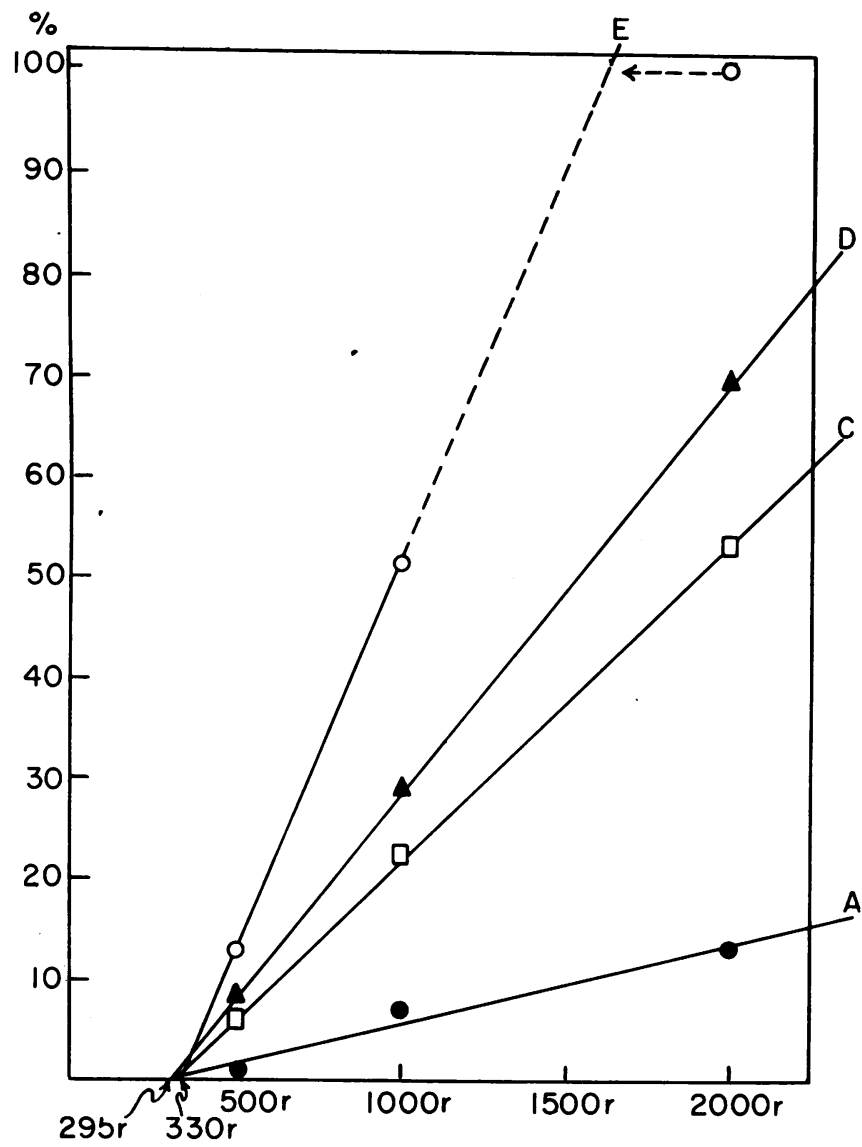

FIG. 4.-The direct proportionality of translocation frequency to $\mathrm{X}$-ray dosage above a minimum in the susceptible postmeiotic stages. The lines are fitted by least squares.

with three virgin females, and transferred to three fresh females at 3-day intervals through four consecutive periods, $a, b, c$, and $d$. Auerbach gave results for both sex-linked and autosomal lethals and mentioned that gross rearrangements followed the same pattern as mutations. The peak mutation rate, both sex-linked and autosomal, occurred in period $b$, and the peak of sterility in period c. Single recombinants from crossing over were absent from period $b$ but were present in period $c$, while complementary classes and bundles of identical crossovers were present only 
皆薏

0.

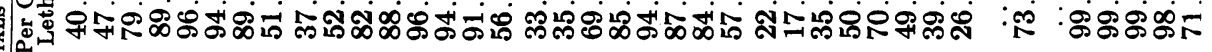

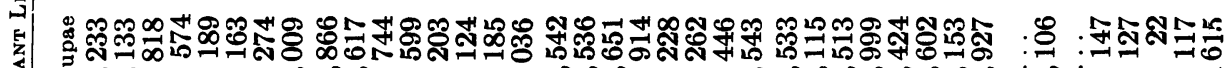
क्षेक i-in

\section{市}

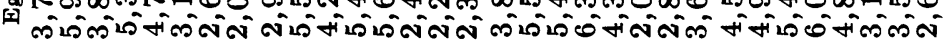

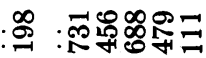
is $\sin ^{-1000}$

\section{离}

$\sum_{0}^{\infty}$ in 0000 H

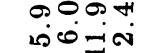

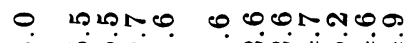

$\infty 0000+\infty$

ocon

$N \infty$

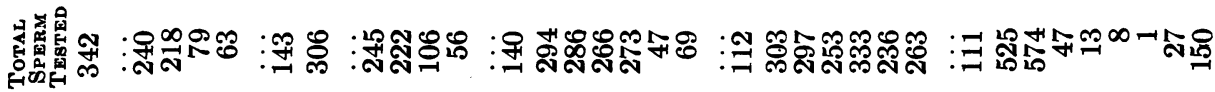

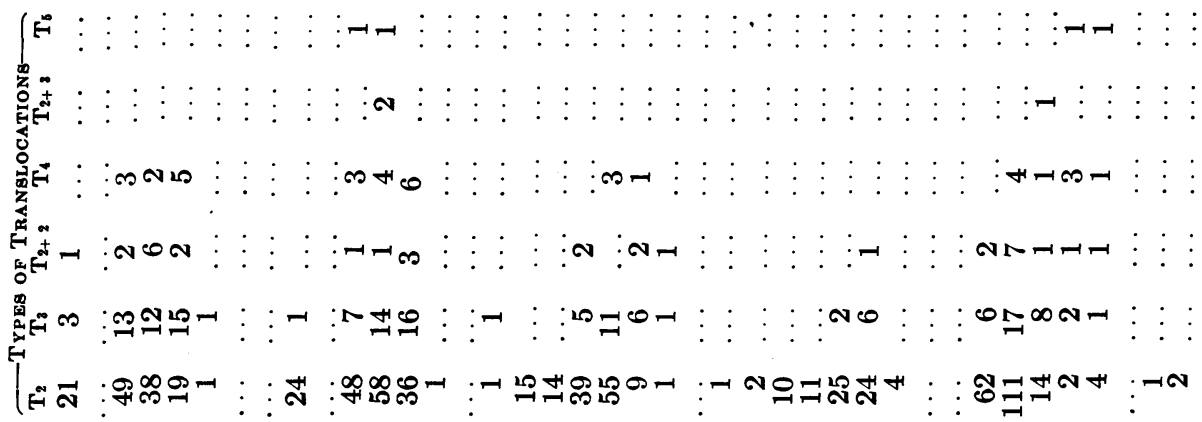

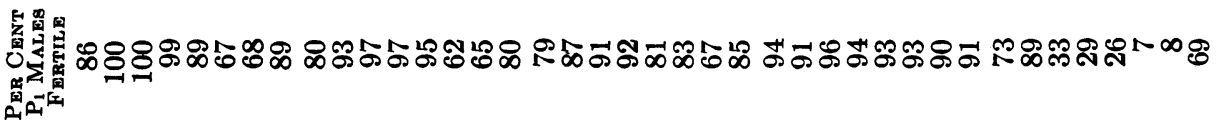




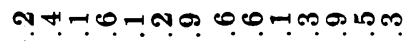

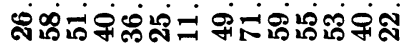

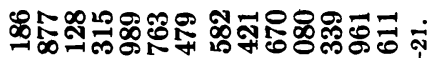

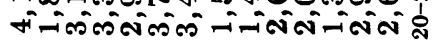

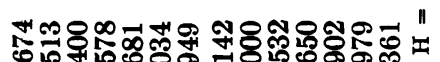

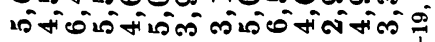
on 0 onto

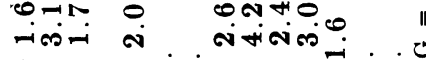
HHH H

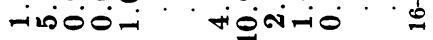

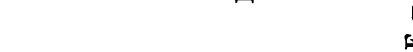

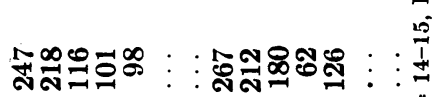
由于. जิ \|ा $\dot{a}$ คสุ์

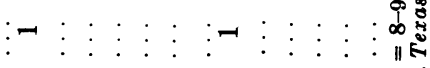

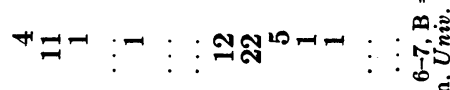

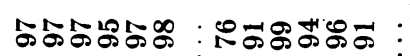

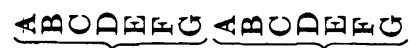
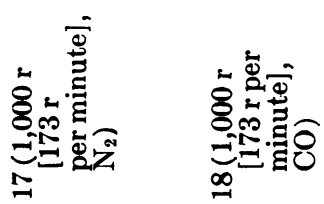

in period $d$. Friesen ${ }^{12}$ proved that $\mathrm{X}$-ray-induced crossing over could occur at meiosis or in spermatogonia with bundles of identical classes from early spermatogonia. Auerbach concludes that the greatest frequency of mutation occurs in some stage of spermeogenesis after meiosis and that the peak sterility occurs in late spermatogonia and the early meiotic stage.

Sobels confirmed this cycle for D. melanogaster..$^{13}$ In addition, he found that azide and cyanide increased mutation rate particularly in the sensitive period. This sensitivity cycle is similar to that worked out by Bonnier and Lüning, except for differences due probably to differences in tech-

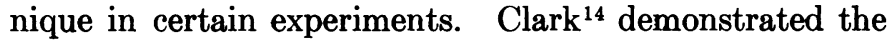
cycle in $D$. melanogaster for sex-linked lethals and translocations. He showed with his experiments that variation in procedure modifies the distribution of abnormalities in successive broods. Auerbach's use of induced crossing over in the male established the relation between the meiotic stage and the amount of damage.

By analogy and by comparison with this other work, especially Auerbach's, with due regard for the slower tempo of development in $D$. virilis, we can approximate the stages in germ-cell development in these young males at irradiation. As indicated on Figure 1, stage A is nearly mature sperm; stages $\mathrm{B}, \mathrm{C}, \mathrm{D}$, and $\mathrm{E}$ are postmeiotic spermeogenesis; stage $\mathrm{F}$ includes meiosis; stage $\mathrm{G}$ is late spermatogonia; and stage $\mathrm{H}$ is spermatogonia. If we compare stages $\mathrm{H}$ through $\mathrm{F}$ with the data for $D$. melanogaster females (Glass ${ }^{15}$ ) or Sciara females (Bozeman and Metz ${ }^{16}$ ) or Habrobracon females (Whiting ${ }^{17}{ }^{18}$ ), we find no essential difference. Where analyses are possible in these cases, there are a few translocations and a moderate number of inversions which survive and an increasing frequency of rearrangements leading to dominant lethals from spermatogonia to meiosis or from oögonia to the first meiotic meta- or anaphase. If stages homologous to stages A through $\mathbf{E}$ of the male occur in females, and the specialized processes in the development would seem to make sperm a special case, they have not been tested for irradiation effects.

Oakberg ${ }^{19}$ showed that in mice late spermatogonia (type B) were very sensitive and therefore were destroyed by low doses of irradiation $\left(\mathrm{LD}_{50} c a .25 \mathrm{r}\right)$. Early sperma- 
togonia (type A) are much more resistant, so that regeneration will occur after much higher doses. Spermatids and sperms are also more resistant. Pontecorvo found a similar situation in Drosophila. ${ }^{20}$ The agreement between the mouse and Drosophila explains stage G (experiment 12), which we regard as late spermatogonia. There were so few sperm available to the inseminated females that only part of the eggs were fertilized.

In young males the number of dominant lethals rises rapidly from early sperma togonia through meiosis (stages $\mathrm{H}$ through $\mathrm{F}$ ) and into spermeogenesis to the stage following meiosis (stage $\mathrm{E}$ ); then it falls again. Translocations are very infrequent until after meiosis (stage F) and then rise rapidly to a peak in stage E. Not all reasons for the difference are clear, but Deschner and Sparrow ${ }^{21}$ have found the same type of situation on irradiating $T$. erectum either with $\mathrm{X}$-rays or with thermal neutrons. The amount of breakage (measured as fragments) and the amount of rejoining (measured as dicentric and ring chromosomes) varied independently. Similar differences in Drosophila in these independent variables will explain the presence of few translocations despite many dominant lethals through meiosis. Probably conditions are much more favorable for rejoining in the normal gene order or joining as a rearrangement in the postmeiotic stages of sperm formation. Deschner and Sparrow discuss some of the factors which might contribute to these differences.

There is another factor which may be important. The sperm of animals undergo a unique change in chromosome composition, for the usual histone protein is replaced by protamine protein. ${ }^{22}$ The high susceptibility of stage E to irradiation damage may be due to the fact that this is the most active stage of protein reorganization as well as of cytoplasmic changes, and the chromosome is more subject to breakage in these unprotected and changing conditions.

Most of the tests in Table 2 were run under similar conditions, using different doses of radiation to test the consistency of the cell cycle and the dose response. Figures 1 and 2 show that the cycle was consistent when measured as dominant lethals or recovered translocations. The frequency of dominant lethals was too great at higher doses to assess the relation to dose. The translocation tests of stages A, C, D, and E from Table 1 and Figure 2 were used to illustrate the relation between X-ray dosage and translocation frequency (Fig. 4). Stages F, G, and H (meiosis back to spermatogonia) were not used, for there were too few translocations. The lines in Figure 4 are fitted to the points by least squares. Only stage $\mathrm{A}$, which is most nearly equivalent to mature sperm in an aged male, might be fitted better by an S-shaped curve. All these curves which best fit these points intersect the base line between 295 and $330 \mathrm{r}$. The 2,000-r value of 100 per cent translocations for stage $\mathrm{E}$ must be disregarded, for there were no intermediate doses between 1,000 and 2,000 r. Many or most of the translocations must result from two or more hits even at the most susceptible stages in spermeogenesis. After the minimum necessary amount of radiation in these susceptible stages, the number of translocations seems to increase proportionally with dosage. The damage measured as translocations to these stages of spermeogenesis with X-rays resembles that of neutrons to mature sperm, except that the damage from the latter is directly proportional to dosage down to zero. ${ }^{7}$

Patterson, Brewster, and Winchester showed that mature eggs of D. melanogaster were more susceptible than immature eggs when radiation damage was 
measured as dominant lethals. ${ }^{23}$ This makes D. melanogaster females similar to Sciara and Habrobracon. Glass ${ }^{15}$ found that there was a much higher frequency of inversions than of translocations produced by irradiating $D$. melanogaster females, showing that the material responded much like Sciara. He found an increase in translocations and Minutes present in irradiated males from the third brood (8-11 days after irradiation) similar to that found by Bonnier and Lüning and by Auerbach for male germ cells. Glass found that the number of Minutes was much smaller in the third brood from irradiated females, again showing greater resistance of earlier stages in oögenesis in Drosophila, again like Sciara and Habrobracon. It is obvious that mature spermatozoa differ from unfertilized Drosophila eggs, but the comparison is not between equivalent stages. Alexander showed that spermatogonia had a much lower mutation rate than mature sperm. ${ }^{1}$ In order to compare males and females, comparable stages in gametogenesis should be used. Mature eggs prior to fertilization stop at metaphase or anaphase of the first maturation division. If we compare the results in females with those in males for stages $\mathrm{H}$ through $\mathrm{F}$, they are very much alike.

In an earlier test, 2-3-day pupae were irradiated with 2,000 $\mathrm{r}$ in 95 per cent $\mathrm{CO}+5$ per cent $\mathrm{O}_{2}{ }^{4} \quad$ Wolsky $^{24}$ studied the inhibition of oxygen consumption of the pupae caused by $\mathrm{CO}$ and found that higher concentrations of $\mathrm{CO}$ were more effective at all stages of pupal development. He showed that $\mathrm{CO}$ inhibition of respiration in Drosophila pupae was light-reversible. Wolsky suggested that changes in amount or activity of the Warburg-Keilin system might explain the change in respiration during pupation. Bodenstein and Sacktor showed that the cytochrome c oxidase activity is reduced drastically in early pupation. ${ }^{25}$. The low point of this U-shaped cycle is about 2-3 days after the onset of pupation; then cytochrome $\mathrm{c}$ increases to the normal adult amount shortly after eclosion of the adult. In our earlier irradiation tests no offspring were produced in stage $A$, and damage measured as translocations was great in stages $\mathrm{B}$ and $\mathrm{C}$ and then fell to 0 in stages $\mathrm{D}, \mathrm{E}$, and F. ${ }^{4}$ The Texmelucan $D$. virilis strain takes 7 days in the pupal stage when irradiated, and the 4-5-day-old pupae used in the present experiment should have about half the amount of cytochrome $\mathrm{c}$ found in the young adult. Pupae were pretreated in $\mathrm{N}_{2}$ (experiment 17) or in $\mathrm{CO}$ (experiment 18) for 8 hours prior to irradiation, so that there was very little residual $\mathrm{O}_{2}$ present during irradiation. Nevertheless, the damage was consistently higher in $\mathrm{CO}$ than in $\mathrm{N}_{2}$. Therefore, the cytochrome system or other agents inhibited by $\mathrm{CO}$ protects the chromosomes against damage which does not depend on an appreciable concentration of $\mathrm{O}_{2}$. This suggests Barron's conclusion that $\mathrm{OH}$ is reacting with cytochrome. ${ }^{26}$ King, Schneiderman, and Sax reported that both $\mathrm{CO}$ and $\mathrm{CO}_{2}$ increased radiation damage when present with $\mathrm{O}_{2}{ }^{27}$ Similar results were obtained with Drosophila by Haas, Dudgeon, Clayton, and Stone. ${ }^{6}$ However, Schneiderman and King showed that $\mathrm{CO}_{2}$ alone was equivalent to radiation in a vacuum. Therefore, the increase in damage occurred when $\mathrm{CO}_{2}$ acted synergistically with $\mathrm{O}_{2}$. In tests 17 and 18 with pupae, the CO inhibits the cytochrome c system or some other active enzyme system which normally protects the chromosome against radiation damage. Even in the absence of $\mathrm{O}_{2}$ from external sources, the inhibition of the cytochrome $\mathrm{c}$ system by $\mathrm{CO}$ increased the radiation damage measured as dominant lethals or translocations above that when the material was treated in $\mathrm{N}_{2}$ 
(Fig. 3). Despite this effect of $\mathrm{CO}$, damage was much less than in other 1,000-r tests.

The cycle was changed so that the peak fell in stage B. Even allowing for the fact that the pupae were irradiated 3-4 days earlier than the young adults, the peak still fell one period earlier than expected. We presume, by analogy with Auerbach's results, that this is the result of difference in amounts of mature sperm which were disposed of before earlier stages could move through.

The pupae in these tests (17 and 18) were irradiated at a lower intensity (173 r per minute) than the adults (1,000 r per minute). Sax, Luippold, and King presented tests that showed an effect of both intensity and fractionation on rearrangement rate in Tradescantia. ${ }^{28}$ Haas et al. ${ }^{6}$ demonstrated that there was also an intensity effect in Drosophila. When experiment 15 is compared with experiments $13 a$ and $13 b$, it suggests a fractionation effect in stages of spermeogenesis of Drosophila, but more tests are necessary to prove this point.

A volume on mutation induction in plants, carried out by the group in Sweden led by Gustafsson, has recently appeared. Ehrenberg and Nybom discussed the direct and indirect effects of radiations of different sorts in that volume. ${ }^{29}$ There are many parallels between their results with plants and our work on D. virilis. ${ }^{4,6,7,30}$ The current tests show that irradiating with poisoning of the cytochrome system with $\mathrm{CO}$ in the absence of an external source of oxygen causes more damage than irradiating in $\mathrm{N}_{2}$ (experiments 17 and 18). Furthermore, replacement of $\mathrm{O}_{2}$ by $\mathrm{CO}$ immediately after irradiation for a 30 -minute period causes a little change in the amount of damage during the cycle, for the results from experiments $13 a$ and $13 b$ are very similar.

Whiting ${ }^{18}$ has recently reported on new experiments on the effect of oxygen on irradiation effects in Habrobracon. She concludes that oxygen increases breakage of chromosomes. Our evidence from Drosophila both for oxygen and for other factors which modify oxidative radicals is in agreement with that conclusion.

Summary.-The relationship between X-ray dosage and genetic damage was determined throughout the meiotic cycle of $D$. virilis. Damage was measured as dominant lethals and translocations. The number of aberrations varies from 20 to 100 fold between stages, depending on the physiological conditions at irradiation (Figs. 1-3). The period (E) just after meiosis is the most susceptible of the stages. The early stages of the maturation of the sperm (E, D, and C) are the periods of differentiation of this unique cell type. Along with the complex changes in the cytoplasm during this period, there occurs the replacement of the histone protein by protamine protein in the chromosomes. The susceptibility of these stages is markedly influenced by modifications in the environment, such as increased amount of $\mathrm{O}_{2}$ or the presence of $\mathrm{CO}$ during irradiation.

During the susceptible period especially (stages A, C, D, and E, Fig. 4), the amount of X-ray damage measured as translocations is directly proportional to dosage above $300 \mathrm{r}$. Very few translocations are produced in premeiotic stages, although many dominant lethals occur. The late spermatogonia (stage G) are so susceptible to radiation injury that many cells in this stage die and few sperm are produced. Radiation damage to the different stages of ooggenesis in the female Drosophila has been shown to be similar to that in Sciara and Habrobracon. The comparable stages in the male, stages $\mathrm{H}$ through $\mathrm{F}$, respond to radiation very much 
as the female. Stages equivalent to stages $\mathrm{E}$ through $\mathrm{A}$ and mature sperm are not present in the female. The enzyme activity as modified by the gaseous environment influenced the amount of damage to pupae (Fig. 4). Even without an external source of $\mathrm{O}_{2}$, irradiation in $\mathrm{CO}$ modified the internal environment and increased radiation damage above that in $\mathrm{N}_{2}$ at all stages. The sensitive stages of the maturation cycle in the male Drosophila are particularly useful in studying the relation between physiological activity and genetic damage from radiations.

We wish to thank Mrs. Florence Wilson, Mr. Perry Mueller, and Mr. Thomas Gregg for technical assistance, and Dr. George Krise for assistance with the $\mathrm{X}$ radiation. The work was supported by the Rockefeller Foundation and the United States Atomic Energy Commission, Contract AT-(40-1)-1323.

1 Mary L. Alexander, Genetics, 39, 409, 1954.

2 C. Auerbach, Z. indukt. Abstamm. Vererb. Lehre, 86, 113, 1954.

${ }^{3}$ K. G. Lüning, Hereditas, 38, 91, 321, 1952.

${ }^{4}$ Wilson S. Stone, Felix Haas, Mary L. Alexander, and Frances E. Clayton, Univ. Texas Publ., No. 5422, p. 244, 1954.

5 J. T. Patterson, Wilson S. Stone, and A. B. Griffen, Univ. Texas Publ., No. 4228, 162, 1942.

${ }^{6}$ Felix L. Haas, Edna Dudgeon, Frances E. Clayton, and Wilson S. Stone, Genetics, 39, 453, 1954.

${ }^{7}$ Wilson S. Stone, Mary L. Alexander, Frances E. Clayton, and Edna Dudgeon, Am. Naturalist, $88,287,1954$.

${ }^{8}$ Kenneth W. Cooper, in Biology of Drosophila, ed. M. Demerec (New York: John Wiley \& Sons, Inc., 1950).

9 A. H. Sparrow, Ann. N.Y. Acad. Sci., 51, 1508, 1951.

${ }^{10}$ Ralph Singleton, pamphlet published by Associated Universities, Inc., 1955.

${ }^{11}$ G. Bonnier and K. G. Lüning, Hereditas, 36, 445, 1950; Hereditas, 39, 13, 1953; K. G. Lüning, Hereditas, 40, 295, 1954.

12 H. Friesen, Biol. Z., 6, 1055, 1937.

13 F. H. Sobels, Z. indukt. Abstamm. Vererb. Lehre, 86, 399, 1955.

14 A. M. Clark, Am. Naturalist, 89, 179, 1955.

${ }^{15}$ Bentley Glass, Genetics, 40, 252, 281, 1955.

16 Martha L. Bozeman and Charles W. Metz, Genetics, 34, 285, 1949.

${ }_{17}$ Anna R. Whiting, Am. Naturalist, 79, 193, 1945; Biol. Bull., 89, 61, 1945.

18 Anna R. Whiting, Genetics, 39, 851, 1954.

19 Eugene F. Oakberg, Radiation Research, 2, 369, 1955.

${ }^{20} \mathrm{G}$. Pontecorvo, Drosophila Information Service, 18, 54, 1944.

${ }^{21}$ Eleanor Deschner and A. H. Sparrow, Genetics, 40, 460, 1955.

${ }^{22}$ Kurt Felix, Am. Scientist, 43, 431, 1955; V. G. Allfrey, A. E. Mirsky, and H. Stern, in Advances in Enzymology, ed. F. F. Nord (New York: Interscience Publishers, Inc., 1955), Vol. 16.

${ }^{23}$ J. T. Patterson, Weldon Brewster, and A. M. Winchester, J. Heredity, 23, 325, 1932.

${ }^{24}$ Alexander Wolsky, J. Exptl. Biol., 15, 225, 1938.

${ }^{25}$ Dietrich Bodenstein and Bertram Sacktor, Science, 116, 299, 1952.

${ }^{26}$ E. S. Guzman Barron, Symposium on Radiobiology (New York: John Wiley \& Sons, Inc., 1952).

${ }^{27}$ Edward D. King, Howard A. Schneiderman, and Karl Sax, these Proceedings, 38, 34, 1952;

Edward D. King and Howard A. Schneiderman, these Proceedings, 38, 809, 1952; Howard A. Schneiderman and Edward D. King, these Proceedras, 39, 834, 1953.

${ }^{28}$ K. Sax and H. Luippold, Heredity, 6, 127, 1952; K. Sax, Edward D. King, and H. Luippold, Radiation Research, 2, 171, 1955.

${ }^{29}$ Lars Ehrenberg, Acta Agr. Scand., 4, 365, 1954; Lars Ehrenberg and Nils Nybom, Acta Agr. Scand., 4, 396, 1954.

${ }^{30}$ Wilson S. Stone, "Mutation,” Brookhaven Symposia in Biology (in press). 